\title{
Entre a loucura e o demoníaco: o discurso contra o espiritismo nas linhas do jornal Santuário da Trindade em Goiás na década de 1920
}

\section{Between madness and demonic: the discourse against spiritsm in the lines of the newspaper Santuário da Trindade in Goiás in the 1920's}

Robson Rodrigues Gomes Filho*

\begin{abstract}
Resumo
O combate ao espiritismo no Brasil na virada do século XIX para o XX está permeado não somente por razões e motivações religiosas, mas fundamentalmente sociais e políticas. A ascensão da medicina psiquiátrica brasileira, concomitante ao próprio espiritismo, uniu-se ao contexto católico de crise pós-padroado no qual a Igreja não só deveria se desdobrar por recursos financeiros aquém do Estado como também no combate a seus adversários religiosos, que, por força de lei, agora eram oficialmente aceitos no país. Neste contexto, a união entre os discursos médico e católico contra um inimigo comum, o espiritismo, se tornou evidente quando se tratou da garantia da soberania de ambos como classe legitimamente portadora tanto da qualidade de verdadeira religião, quanto de verdadeira ciência. No entanto, em Goiás a ausência de uma classe médica forte deu ao catolicismo a possibilidade de ser o paladino deste combate, fazendo-o, de modo especial, na década de 1920, através do jornal Santuário da Trindade, editado em Campinas pela Congregação Redentorista. Em vistas disso, o presente artigo tem como objeto de análise o discurso de combate ao espiritismo pelo referido periódico católico, tomando como ponto de partida principal a união de seus argumentos religiosos com os argumentos médicos-psiquiátricos desenvolvidos em todo o Brasil nas primeiras décadas do século XX.
\end{abstract}

Palavras-chave: Espiritismo. Medicina. Redentoristas. Loucura.

\section{Abstract}

The combat against Spiritism in the transition from the $19^{\text {th }}$ to the $20^{\text {th }}$ century in Brazil is permeated not only by religious reasons and motivations, but

${ }^{*}$ Doutorando da Universidade Federal Fluminense. Professor efetivo do curso de História na Universidade Estadual de Goiás - UnU Morrinhos. E-mail: robson.educacao@yahoo.com.br 
fundamentally by social and political ones. The rise of Brazilian psychiatric medicine, concomitant to Spiritism, was joined to catholic context of the post-ecclesiastical patronage crisis, in which the Church besides falling back to the State for financial resources, should also combat their religious opponents, whose, by Law, were officially accepted in the country. In this context, the union between the catholic and medicinal discourses against a common enemy, the Spiritism, became evident when it came to ensuring to both sovereignty as the legitimate bearers of true religion and true science. However, in Goiás the absence of a strong medical class brought to Catholicism the possibility to be the paladin of this combat, doing it, especially, in the decade of 1920, through the newspaper Santuário da Trindade, edited by Redemptorists Order. In view of this, the present article has, as object of analysis, the discourse to combat Spiritism by said Catholic newspaper, taking as the main starting point the union between religious and medical discourses developed in the first decades of the $20^{\text {th }}$ century.

Keywords: Spiritism. Medicine. Redemptorists. Madness.

\section{INTRODUÇÃO}

A história do espiritismo no Brasil está marcada não somente pela ascensão de uma nova forma de entendimento e experiência religiosa, mas fundamentalmente pela oposição entre Estado, Igreja e instituições médicas. Da parte do Estado, embora de maneira pouco clara - uma vez que "espiritismo" em fins do século XIX não gozava de definição objetiva -, a prática espírita foi condenada como crime por meio do Artigo 157 do Código Penal de 1890. Segundo o documento, constituía-se crime contra a saúde pública: ${ }^{1}$

Praticar o espiritismo, a magia e seus sortilegios, usar de talismans ecartomancias para despertar sentimentos de odio ou amor, inculcar cura de moléstias curaveis ou incuraveis, emfim, para fascinar e subjugar a credulidade publica:

Penas - de prisão cellular por um a seis mezes e multa de $100 \$$ a $500 \$ 000$. $\S 1^{\circ}$ Si por influencia, ou em consequencia de qualquer destes meios, resultar ao paciente privação, ou alteração temporaria ou permanente, das faculdades psychicas:Penas - de prisão cellular por um a seis annos e multa de $200 \$$ a $500 \$ 000 .^{2}$

Tal destacamento de crime, ao que se pode notar, estava ligado a duas outras esferas que ultrapassavam os limites do poder meramente civil: a re-

1 Destacamos que as citações de fontes no presente artigo mantêm a grafia do documento original. 2 BRASIL. Subsecretaria de Informações. Artigo 157. Código Penal Brasileiro. Rio de Janeiro: Senado Federal, 1890. 
ligiosa e a médica. Por um lado, há uma denotação abertamente religiosa no código penal quando o mesmo se refere ao mencionado crime a partir da "magia", "sortilégios", "cartomancia" e "despertar da credulidade". Tais referências, evidentemente ligadas a pressupostos religiosos, conotam um paradoxo para a implantação da República no Brasil: se, por um lado, a nova Carta Constitucional de 1891 separava os poderes civil e eclesiástico, pondo fim ao regime de padroado, por outro, o Código Penal, promulgado no ano anterior, mantinha-se ainda ligado, em partes, à soberania católica.

A justificativa para a manutenção da proibição de uma expressão religiosa no Brasil, quando já vigorava na Constituição brasileira a "liberdade de culto e fé religiosa", ${ }^{3}$ se deu a partir da alegação de que o espiritismo não poderia ser considerado uma "religião" ou "culto", mas antes, "charlatanismo". Em processo criminal contra o movimento messiânico de Santa Dica, ${ }^{4}$ por exemplo, o chefe de polícia de Goiás, Celso Calmon Nogueira da Gama, justifica a condenação da taumaturga por "prática do espiritismo", em 1926, fazendo constar o seguinte em seu relatório:

Não se venha, entretanto, dizer que estamos diante de um culto, isto é, que esta série de atos ilícitos praticados pelos indiciados constitua um culto, que a Constituição, em seu Artigo 72 \$3ํo garante, porquanto isso seria um manifesto desconhecimento dos elementos que compõe uma religião. ${ }^{5}$

Por outro lado, no que se refere à esfera da medicina, o mesmo Artigo 157 do Código Penal toca em elementos médicos importantes para a condenação das práticas espíritas: em primeiro lugar, o título do Artigo a que se refere o crime é intitulado "Capítulo III: Dos crimes contra a saúde pública"; em segundo lugar, o referido artigo se encontra, propositalmente, entre a "prática da medicina sem registro legal" (Art. 156) e "a prescrição de elementos ou substâncias curativas sem licença" (Art. 158).

A presença de tais preocupações com a "saúde pública" no Código Penal Brasileiro, já em fins do século XIX, marcou a ascensão definitiva da classe médica brasileira, que há muito pairava nas esferas de poder do país.

3 Na seção II, Artigo 72, parágrafo terceiro da Constituição brasileira de 1890, rege-se que: "Todos os indivíduos e confissões religiosas podem exercer pública e livremente o seu culto, associando-se para esse fim e adquirindo bens, observadas as disposições do direito comum” (BRASIL, 1891. Art. 72, § 3)

4 Sobre o movimento messiânico em questão, ver: GOMES FILHO, R. O movimento messiânico de "Santa Dica" e a Ordem Redentorista em Goiás (1923-1925). 2012. 181 f. Dissertação (Mestrado em História) - Instituto de Ciências Humanas e Sociais, Universidade Federal de Ouro Preto, Mariana, 2012.

5 Celso Calmon Nogueira da Gama. Chefe de polícia. Processo 651, maço 9. Cartório de Crime de Pirenópolis (GO). 1925. $69 \mathrm{f}$ 
Na virada do século XIX para o XX, mais precisamente, um ramo especial da medicina ganhava força no Brasil: a psiquiatria.

Segundo Angélica Almeida,

a Psiquiatria procurou mostrar-se detentora de um conhecimento de base empírica, de acordo com as exigências da época, extraído das universidades e do debate científico entre seus pares. Esse conhecimento seria capaz de transformá-la no instrumento mais adequado para prevenir, diagnosticar e tratar a loucura e de desmistificar o poder sobrenatural dos tratamentos espíritas, comprovando a sua ineficácia. ${ }^{6}$

Corroborando com essa reflexão, Artur Isaia ${ }^{7}$ acredita que foram os médicos psiquiatras os principais responsáveis pela censura às práticas espíritas no Brasil. A produção de uma vasta literatura relacionando os fenômenos espíritas a doenças psíquicas marcou a legitimação do discurso médico, que daria igual sustentação tanto à repressão do Estado quanto à condenação religiosa. Para Isaia,

livros e manuais didáticos passaram a considerar o espiritismo como um perigo à saúde pública, a demandar uma pronta ação repressiva das autoridades. Nesse sentido, os médicos credenciavam-se como os mais abalizados a assessorar o Estado, partindo de medidas conducentes para sanear o espaço público e livrá-lo de mais um foco difusor da doença mental. ${ }^{8}$

É importante ressaltar que o combate ao espiritismo no Brasil pela medicina psiquiátrica se deu em campanha da mesma forma que se combatia doenças e vícios, vistos como símbolo, antes de tudo, do atraso do Brasil em face do "progresso" almejado. Segundo se fez constar em diversas teses da Faculdade de Medicina do Rio de Janeiro, analisadas por Artur Isaia,

o combate ao espiritismo deve ser igualado ao que se faz à sífilis, ao alcoolismo, aos entorpecentes (ópio, cocaína etc.), à tuberculose, à lepra, às verminoses, enfim, a todos os males que contribuem para o aniquilamento das energias vitais, físicas e psíquicas do nosso povo, da nossa raça em formação. ${ }^{9}$

Em todo caso, o fato é que há séculos as práticas de curandeirismo, xamanismo e incorporações de espíritos ou entidades sobrenaturais eram re-

6 ALMEIDA, A. Uma fábrica de loucos: psiquiatria x espiritismo no Brasil (1900-1950). Tese (Doutorado em História) - Instituto de Filosofia e Ciências Humanas, Universidade Estadual de Campinas, Campinas, 2007. p. 67.

7 ISAIA, A. O espiritismo nas teses de medicina na faculdade do Rio de Janeiro. História Revista, Goiânia, vol. 2, n. 1, 2007.

8 Ibidem, p. 63.

9 MARQUES, 1929 apud ISAIA, op, cit., p. 71. 
correntes no Brasil. Para tanto, não há dúvida da significativa contribuição das práticas religiosas indígenas e africanas. Todavia, o que se denominou "espiritismo" - enquanto doutrina filosófica e religiosa de pretensões científicas - , difundido a partir de Alan Kardec, apenas no final do século XIX tomou forma no Brasil de fato, ${ }^{10}$ tomando como ponto de partida justamente um significativo setor da "cura": a homeopatia.

Segundo Veloso, ${ }^{11}$ os primeiros precursores do espiritismo no Brasil, curiosamente, foram os praticantes da homeopatia, já nas primeiras décadas do Oitocentos. Para tanto, nomes como Mariano José Pereira da Fonseca (o Marquês de Maricá), Alexandre José Mello de Moraes, dr. Benoit Jules Mure e dr. João Vicente Martins, entre outros, a partir da difusão de terapias médicas alternativas, seja através de plantas ou mesmo de "passes" de energias magnéticas, prepararam um território já bastante propício para o assentamento do espiritismo europeu no Brasil. Para Veloso,

A Homeopatia começava a ser discutida como terapia alternativa, constituindo-se nos meios cultos do país como fonte receptiva para novas ideias, sendo dessa forma o embrião para a formação dos ideais espíritas em terras brasileiras, dada à similitude dos princípios dessa ciência com o Espiritismo no que diz respeito aos fluidos e energias magnéticas. ${ }^{12}$

Entretanto, no que diz respeito aos fenômenos propriamente espíritas, ao estilo importado do kardecismo europeu, especialmente das "rotações elétricas" e "mesas girantes", as primeiras notificações no Brasil se deram somente na segunda metade do século XIX. Na imprensa escrita, segundo Airton Veloso,

O Jornal do Comércio do Rio de Janeiro, em sua edição do dia 14.06.1853, é o primeiro jornal brasileiro a publicar matéria comentando os fenômenos das mesas girantes. No mesmo jornal, em edição do dia 30.06.1853, publica-se a matéria intitulada "A Rotação Elétrica" sobre os fenômenos que empolgavam Paris, os Estados Unidos, México, Londres, Viena e Berlim. Outros periódicos como O Diário de Pernambuco e O Cearense ventilariam notícias sobre os fatos considerados espetaculosos. ${ }^{13}$

10 Ressaltamos que, embora estejamos trabalhando com a noção de espiritismo enquanto a doutrina kardecista difundida no Brasil, o fato é que ainda no início do século XX - período de nosso recorte - não havia qualquer distinção clara entre essa doutrina e as práticas indígenas e africanas que ocorriam no Brasil há séculos. Desse modo, o que se condenou, especialmente por parte dos seguimentos católicos, foi o espiritismo "genérico", sem qualquer delimitação doutrinária, filosófica ou religiosa do mesmo.

11 VELOSO, A. Os primórdios do Espiritismo em Goiás. Goiânia: FEEGO, 2010.

12 VELOSO, op, cit. p. 69

13 VELOSO, op, cit. p. 71 
Em todo caso, alguns nomes em específico se tornariam mais conhecidos no Brasil, dentre os quais podemos citar: Eurípedes Barsanulfo (1880-1918), Zilda Gama (1878-1969), Yvonne do Amaral Pereira (1900-1984) e aquele que se tornou mais conhecido mundialmente Chico Xavier (19102002). Tais personagens, dentre muitas outras, tiveram suas trajetórias sociais, políticas e religiosas marcadas, sobretudo, pela perseguição, uma vez que, como vimos argumentando, três das mais poderosas instituições sociais e políticas se juntaram no cerceamento das práticas espíritas no Brasil: a Igreja, o Estado e a Medicina. Em Goiás, especificamente, tal perseguição não fugiu muito à regra, não obstante estivesse, como todo objeto histórico, carregada de singularidades tão caras às pesquisas historiográficas, cujas características dotam de significativa riqueza o ofício do historiador.

\section{OS PRIMÓRDIOS DO ESPIRITISMO EM GOIÁS}

Embora o espiritismo já marcasse presença no Brasil desde a segunda metade do século XIX, em Goiás tais tendências só ganhariam espaço a partir da entrada do século XX.O primeiro caminho que, sem dúvidas, levou à chegada do espiritismo de maneira mais substancial ao estado de Goiás foi a estrada de ferro.

A construção das ferrovias em Goiás é comumente vista pela historiografia goiana como um marco na construção real do ideário de "progresso" do estado. Segundo Barsanufo Gomides Borges,

a E. F. Goiás foi o primeiro meio de transporte moderno do Estado e a principal porta de comunicação com o Centro-Sul do país. [...] Com a chegada do trem de ferro, a Maria Fumaça com sua cauda de aço serpenteando pelo sertão com seu silvo estridente despertava Goiás de séculos de isolamento ${ }^{14}$.

Esta simbolização da estrada de ferro como precursora da modernidade goiana se dá especialmente pelo fato de ela romper de vez a imagem de Goiás como um estado isolado, seja da rota do capital brasileiro e mundial, seja dos trilhos do progresso que irradiava desde o centro-sul do Brasil.

Todavia, além do significativo crescimento econômico do estado, advindo da escoação da produção agrícola e pecuária, as estradas de ferro e rodovias traçadas em Goiás trouxeram consigo uma expressiva leva de migrantes, advindos especialmente do centro-sul do país em busca de terras

14 BORGES, apud CHAUL, N. F. Caminhos de Goiás: da construção da decadência aos limites da modernidade. Goiânia: Editora da UFG, 2002. p. 131. 
baratas para se fixarem. $\cdot{ }^{15}$ Esta importante leva migratória representava não somente a tentativa de superação do déficit populacional de Goiás, mas fundamentalmente dava aos goianos a sensação de que seu estado, antes em isolamento e atraso, se tornava esperança de futuro mesmo para aqueles que já estavam em lugares cujo progresso já era parte da realidade.

Não obstante a significação de progresso dada à implantação da ferrovia em Goiás, e com ela a leva migratória que comporia o destacado século XX goiano, junto aos migrantes, novas ideias, tendências e visões de mundo se fundiam ao tradicional modo de vida goiano. Dentre as muitas ideias e práticas advindas do centro-sul brasileiro, destacou-se o espiritismo.

Segundo consta no jornal Goiaz Espírita, em uma edição de outubro de 1948, o espiritismo teve sua fundação em território goiano na Cidade de Goiás, a partir de experiências com as "mesas girantes", no ano de 1886. A razão pela qual a capital do estado parece ter sido o centro primeiro de irradiação do espiritismo parece se dar pelo fato do considerável volume de informações que, na contramão da expressa maioria do restante do estado, circulava na Cidade de Goiás, a partir das quais - especialmente em se contando com uma elite goiana que se formava na maioria das vezes fora do estado - dava-se à cidade um certo "cosmopolitismo" minimamente singular. Segundo Veloso,

Dentro desse cenário de cultura, já estavam instalados naquela histórica cidade, o Liceu de Goiás desde 1847, a Faculdade de Direito, a Primeira Biblioteca em 1850, o Gabinete Literário em 1864, sem contar uma quantidade considerável de jornais que circularam em épocas variadas tais como O Monitor Goiano, tendo como diretores Feliz Bulhões e o tenente José Inácio de Oliveira, Correio Brasiliense ou Armazém de Literatura, A Voz do Povo, Diário de Notícias, Diário Oficial, a revista A Província de Goiás e outros. ${ }^{16}$

Em todo caso, a fundação propriamente do espiritismo kardecista goiano se deu somente em 1909, com a composição do grupo Amigo dos Sofredores, ${ }^{17}$ na cidade de Goiás, pelos senhores Antônio Cupertino Xavier de

15 Segundo Chaul (2002, p. 128): “A marcha do café e a ascensão da urbanização e industrialização do Centro-Sul do país reorientaram e expandiram as bases econômicas de regiões que estavam interligadas ao processo nacional, como foi o caso de Goiás. A elevação dos preços e a ocupação das terras do Centro-Sul, por causa da marcha do café, fizeram com que, após a ocupação do sul de Minas e do Triângulo Mineiro, levas e levas de paulistas e mineiros penetrassem no território goiano com o intuito de adquirir terras, a preços baixos, para desenvolverem a agropecuária".

16 VELOSO, op, cit. p. 108.

17 Segundo Veloso (op, cit., 2010, p. 108), o grupo espírita “Amigo dos sofredores” só adquiriu personalidade jurídica em Goiás em 1924. 
Barros, Luiz M. de Camargo Jr., José Olímpio Xavier de Barros, José Teotônio Dias e o professor José Malaquias do Nascimento. Dentre estes nomes, o de maior destaque é José Olímpio Xavier Barros. ${ }^{18} \mathrm{Em}$ poucas décadas, porém, uma considerável quantidade de centros espíritas se espalharia pelo estado de Goiás, em sua grande maioria frutos da influência de Eurípedes Barsanulfo, em Sacramento (MG),e José Olímpio Xavier Barros, na cidade de Goiás.

Segundo Veloso, ${ }^{19} \mathrm{os}$ primeiros centros espíritas em Goiás, até a década de 1920, foram fundados na seguinte sequência: em 1914, Centro Espírita na zona rural de Catalão; em 1921, Centro Espírita Alarcão em Anápolis; em 1923, Centro Espírita Batuíra, Verdade e Luz em Itaçu; em 1927, Centro Espírita Eurípedes Barsanulfo em Caldas Novas, Centro Espírita Amor e Fraternidade em Catalão, Centro Espírita São Vicente de Paulo em Anápolis; em 1928, Centro Espírita do Patrimônio da Terra Vermelha no distrito de Nova Aurora; Grêmio Espírita Paz e Fraternidade em Ipameri; em 1930, Grêmio Espírita Eurípedes Barsanulfo União, Amor e Luz no distrito de Areião (Corumbaíba).

Por conta do nosso recorte (a publicação do jornal Santuário da Trindade), tomamos como dados apenas os centros fundados até a década de 1920. Todavia, mesmo aqui já é possível notarmos duas características importantes: 1) a fundação de centros espíritas em Goiás teve uma aceleração considerável na década de 1920, passando de apenas um, na década anterior, para sete $;^{20} 2$ ) a maior parte da fundação de centros espíritas em Goiás até o referido período ocorreu na região sul do estado, ao que nos parece, tanto por ser a região mais populosa quanto por ser a mais desenvolvida economicamente, o que dá vazão à nossa hipótese de que a irradiação do espiritismo em Goiás tem relação direta com o processo migratório da região sul-sudeste do Brasil para a região centro-sul do estado.

Estas constatações nos levam a reflexões importantes: de um lado, a estreita relação entre a modernização de Goiás - com suas estradas de ferro, desenvolvimento econômico e, por conseguinte, atração de processos migratórios para o estado - e a chegada do espiritismo, protestantismo e outros adversários importantes do catolicismo goiano, de outro, o combate a

18 Segundo Veloso (op, cit., 2010, p. 109), foi José Olímpio um dos principais precursores do espiritismo kardecista goiano, realizando trabalhos na cidade de Goiás desde o início do século XX, sendo citado até mesmo no periódico Tribuna Espírita, do Rio de Janeiro, por Cora Coralina, em um artigo de 15 de fevereiro de 1909.

19 VELOSO, op, cit. p. 109-110.

20 Lembrando que estamos trabalhando com os dados colhidos por Veloso (op, cit. 2010) em pesquisa ainda insipiente, o que significa que este número pode ser ainda maior, especialmente se pensarmos em grupos espíritas não oficializados em "centros". 
tais adversários realizado justamente na década de 1920 pelo jornal Santuário da Trindade, cuja defesa dos mesmos processos de modernização geram uma problemática sugestiva para interessantes investigações acadêmicas. Nisto, quando pensamos as teses médicas combatendo também o espiritismo, cujo argumento fundamental repousa no ideário de modernização, progresso e ciência, em franco alinhamento com os discursos católicos, tal problemática se torna ainda mais urgente e necessária de ser refletida e pesquisada.

\section{EVITAR A LOUCURA, COMBATER O ESPIRITISMO: DAS TESES DE MEDICINA ÀS LINHAS CATÓLICAS DO SANTUÁRIO DA TRINDADE}

A ascensão da medicina, especialmente a medicina psiquiátrica, na virada do século XIX para o XX está permeada não somente de avanços acadêmicos e científicos, mas fundamentalmente de uma luta por espaço de legitimidade dentro do Brasil, cuja competição se deu especialmente contra as práticas populares de curandeirismos e crenças religiosas em eventos místicos e/ou miraculosos. Neste campo de lutas e competições pela competência e legitimidade da cura, a medicina brasileira encontrou na religião tanto um aliado como um adversário. Se, por um lado, o espiritismo - em franca ascensão, cujo discurso extrapolava o campo da crença religiosa, atingindo fundamentalmente o campo da ciência - representava um adversário a ser combatido em prol da "salubridade pública", por outro, o catolicismo representava a religião não supersticiosa (portanto racional) por excelência, política e socialmente aliada ao Estado e à Academia Brasileira. Estava formada aí uma aliança que, embora incomum, foi bastante eficaz contra o avanço do espiritismo no Brasil.

A oposição entre o discurso médico e o espiritismo pode ser encarada como uma clara competição por competência científica no que tange à cura de doenças. Segundo Isaia, "encarando o espiritismo como totalmente oposto à ciência e à medicina, os médicos partiram para jogos identitários, capazes de simplificar e radicalizar a realidade". ${ }^{21}$ Enquanto o espiritismo buscava se legitimar como ciência, tratando especialmente dos problemas psíquicos, tendo-os como casos de "obsessão espiritual”, a medicina psiquiátrica brasileira caminhava nos passos do organicismo europeu, cuja argumentação era de que, assim como ocorria com doenças físicas, as psicológicas eram passíveis de contágio, o que explicaria as crenças e possessões espirituais e místicas como casos de histerias coletivas.

21 ISAIA, op, cit. p. 64. 
O fato é que estamos diante de uma disputa por espaço e poder social, político e religioso dentro de um campo também em franca ascensão no Brasil: a ciência. Se, por um lado, a medicina se utilizou do discurso científico-acadêmico como critério de demarcação entre sua prática autorizada e a dos curandeiros - detentores de saberes populares e cura por meio de plantas e rezas tradicionais ${ }^{22}$ - o espiritismo, por outro, balizou-se não somente na cura por meio de sessões espirituais, mas em uma singular tentativa de se fazer igualmente científico, especialmente no que tange o trato com a "loucura". Desse modo,

A Psiquiatria procurava legitimar-se no campo científico. O Espiritismo, por ser uma religião com pretensões científicas, além de tentar se inserir no campo religioso também buscava reconhecimento no campo científico. Muitas teorias desenvolvidas pelos espíritas tinham pontos de contato com a Psiquiatria: as relações mente-corpo, a causas da loucura, bem como seus modos de tratamento e prevenção. Configurava-se uma disputa pelo poder e autoridade científica para se pronunciarem sobre esses assuntos. ${ }^{23}$

Em resumo, podemos acrescentar ao debate alguns fatores que permearam a progressiva tentativa de, no Brasil, o espiritismo disputar espaços de poder com a medicina psiquiátrica. De modo particular, conforme destaca Bernardo Lewgoy, ${ }^{24}$ os intelectuais praticantes da religião espírita passaram a defender uma espécie de "nexo significativo" entre ciência e religião - movimento oposto ao que no mesmo século XIX fazia o ultramontanismo católico. ${ }^{25}$ Tal nexo, especialmente no que diz respeito à tentativa de dissolução das barreiras entre a ciência médica e o espiritismo, pode ser analisado a partir de três fatores fundamentais: 1) a ênfase na terapêutica; 2) prescrição mediúnica de receitas; 3) a invocação de uma chamada "parapsicologia" ${ }^{26}$

22 Sobre a prática da benzedura e suas relações com a medicina, ver: DIAS, M. Curandeiros, feiticeiros e práticas alternativas de cura na Comarca das Mortes na segunda metade do oitocentos. Revista Ágora, Vitória, n. 9, 2009; FARINHA, A. As transformações da prática de benzimento em Anápolis (1979-2004). Dissertação (Mestrado em História) - Faculdade de História, Universidade Federal de Goiás, 2012.

23 ALMEIDA, op, cit. p. 97.

24 LEWGOY, B. Representações de ciência e religião no espiritismo kardecista: antigas e novas configurações. Civitas, Porto Alegre, vol. 6, n. 2, jul./dez. 2006.

25 Sobre a relação entre o ultramontanismo e a modernidade/ciência, ver: MATA, S. da. Entre Syllabus e Kulturkampf: revisitando o "reformismo" católico na Minas Gerais do Segundo Reinado. In: CHAVES, C. M.; SILVEIRA, M. A. (Org.) Território, conflito e identidade. Belo Horizonte: Argvmentvm, 2007.

26 "A parapsicologia - com fortes ingredientes positivistas - tornou-se um terreno de disputa que permitia definir uma instância externa de julgamento e prova da verdade ou da fraude dos fenômenos espíritas. Como veremos, iniciativas posteriores propuseram o abandono desse marco de discussão em nome de uma posição demarcacionista, onde materialistas e cientistas não-espíritas tenham o seu lugar próprio e separado, tanto quanto os espíritas, em nome da especificidade de domínios e sistemas de conhecimento." LEWGOY, op, cit. p.152. 
Estes três fatores, conforme se pode notar, fomentaram na atividade espírita de cura e terapia uma caracterização singular de "medicina", tornando possível até mesmo o surgimento de "hospitais psiquiátricos" espíritas, a partir dos quais um dos principais motivos de acusação contra o espiritismo (a loucura), tornara-se uma suposta atividade de cura, paradoxalmente oferecida pelos mesmos médiuns outrora acusados.

Neste sentido, não parece forçoso propor que exista uma relação minimamente estreita entre a ascensão e sucesso da Medicina psiquiátrica no Brasil e o combate ao espiritismo, uma vez que, apoiada por duas das mais importantes instituições políticas e sociais do Brasil (o Estado e a Igreja Católica), a medicina psiquiátrica brasileira parece ter se utilizado do espiritismo como elemento expiatório, cujo sacrifício resultaria na legitimidade dos médicos como verdadeiros "bandeirantes" da limpeza necessária no sertão goiano. Conforme corrobora Artur Isaia: "como um 'grande hospital', o Brasil requeria a presença ostensiva dos médicos, a fim de tentar reverter o quadro degradante de uma população sucumbida a toda a sorte de males orgânicos". ${ }^{27}$

Neste sentido, a pintura imaginada da situação de "atraso" em Goiás corroborava muito com os relatórios médicos acerca da suposta insalubridade do sertão goiano, marcado, sobretudo, pelo "isolamento, resistência ao progresso, doença, resistência a mudanças, uso da terapêutica popular, apatia e acomodação". ${ }^{28}$ Essa estreita relação entre saúde pública e progresso esteve presente nas agendas de discussão de boa parte da intelectualidade brasileira, especialmente àquela voltada à saúde pública e à medicina psiquiátrica. $\mathrm{O}$ estado de Goiás, representante visível do imaginário da insalubridade do sertão brasileiro, foi alvo de relatórios médicos, discussões políticas e debates intelectuais, ${ }^{29}$ a partir dos quais a necessidade de integração do estado à marcha do progresso brasileiro se tornou um importante foco nas discussões que tangiam as relações entre "medicina" e "progresso".

27 ISAIA, op, cit. p. 69.

28 CASAZZA, I. F. Brasil, um imenso hospital? In: USOS DO PASSADO: XII ENCONTRO REGIONAL DE HISTÓRIA DA ANPUH. Rio de Janeiro, 2006. p. 2.

29 Um dos principais e mais polêmicos relatórios médicos sobre a questão da salubridade do interior brasileiro foi realizado por Belisário Pena e Arthur Neiva em 1912 (publicado em 1916), promovido pelo Instituto Oswaldo Cruz por requisição da Inspetoria de Obras Contra as Secas. O citado relatório, cuja descrição da situação sanitária de Goiás apontou para os mais diversos problemas de salubridade pública, foi expressamente contestado pelo periódico A Informação Goyana, a partir do qual um interessante debate sobre a situação e necessidades de progresso em Goiás se tornou possível e expresso. Sobre o assunto, ver: CASAZZA, op, cit. 
Desse modo, aproveitando-se de ensejo do discurso do progresso no Brasil, acatado tanto pelo Estado quanto pela própria Igreja Católica, a Medicina tomou a dianteira no discurso do progresso da nação brasileira, tornando-se o verdadeiro paladino da modernização social através da higienização das práticas, costumes e crenças no Brasil. A essa altura, o espiritismo, bem como as crenças curandeirísticas, xamanistas e demais práticas não católicas presentes no Brasil, tornavam-se não somente sinal de atraso e decadência social, mas, sobretudo, um inimigo a ser combatido em prol do progresso da nação.Nas palavras de Isaia: "o espiritismo era remetido pelo catedrático de psiquiatria da Faculdade de Medicina do Rio de Janeiro [Henrique Roxo] à condição de patologia mental denunciadora do atraso nacional". ${ }^{30}$

$\mathrm{O}$ argumento que relaciona o espiritismo à superstição foi largamente utilizado tanto pela medicina quanto pelo catolicismo. Em ambos os discursos, porém, é inegável um elemento em comum: a preocupação com o "atraso" nacional. Em suas dezenas de artigos criticando as "supersticiosas" religiosidades não católicas, o Santuário da Trindade se utilizou várias vezes de argumentos voltados para a contraposição entre a "ignorância" - símbolo do atraso e letargia social ${ }^{31}$ - e a "civilização", marcada por uma religião "racional e institucionalizada", bem como por um desejo de uma sociedade "culta" e "civilizada", portanto, imersa no progresso. Tais posicionamentos podem ser visualizados em alguns trechos de artigos do próprio jornal, utilizados como argumentos contra o movimento messiânico de Santa Dica, ocorrido em Goiás entre 1923 e 1925: ${ }^{32}$

\footnotetext{
Como é possível que no século XX haja ainda fanáticos que acreditam numa mulher doente e visionária? ${ }^{33}$

É incrível que no século 20 ainda haja pessoas que se prestem para taes babozeiras. Mais uma vez se prova que a falta de religião e a ignorância do catecismo arrastam os homens para a superstição e fanatismo. Mais uma vez pedimos providências ao Governo contra essa mancha para os foros civilizados de Goyaz. ${ }^{34}$
}

30 ISAIA, op, cit. p. 73.

31 Sobre a tese da decadência, atraso e letargia social, ver: PALACIN, L. O século do ouro em Goiás. Goiânia: Ed. Da UCG, 1994.

32 Sobre as relações entre os redentoristas e o movimento messiânico de Santa Dica em Goiás, ver: GOMES FILHO, op, cit.

33 JORNAL SANTUÁRIO DA TRINDADE. Campininha das Flores: Coleção Convento Santo Afonso, 19221925. Ano 3, n. 73. 30 ago. 1924.

34 JORNAL SANTUÁRIO DA TRINDADE. Campininha das Flores: Coleção Convento Santo Afonso, 19221925. Ano 3, n. 93. 17 jan. 1925. 
Não é isso uma vergonha para o nosso século tão adeantado que se julga livre de toda a superstição e fanatismo? ${ }^{35}$

Os motejos e sarcasmos indicando nomes e narrando as homenagens prestadas à Dica na capital do estado, são verdadeiramente desconcertantes e humilhantes para os foros cultos de Goyaz [...] E a história não ficará nisso: daqui a dias essa imprensa collocará nosso estado no rol das tribos selveticas que acreditam em feitiçarias e bruxas e nós teremos que engulir a pílula porque os próprios goyanos deram a mão à palmatória. ${ }^{36}$

Por parte do Estado, ainda no que se refere ao mesmo movimento messiânico em questão, o chefe de polícia de Goiás, Celso Calmon Nogueira da Gama, em seu relatório, transparece o mesmo discurso cujo âmago corresponde à oposição entre "superstição" e "progresso":

O crime de que trata este inquérito, ex-ofício instaurado, é o que nestes últimos tempos, mais atentou contra a nossa capacidade intelectual, contra a nossa moral e contra a saúde pública. A superstição, oriunda de falsas ideias religiosas, é a sua causa principal. Parecia-nos que essa matéria de superstição devia estar, de muito, relegada para um esquecimento completo, ante a nossa cultura, dia-a-dia mais aperfeiçoada, pois ela só medra ante a ignorância [indecifrado]. A superstição [indecifrado] [----]. É uma teoria, aliás, aceita em todos os países cultos, mas [indecifrado] de quando em quando surge um fato qualquer originário nas errôneas ideias que nos [indecifrado] o nome do povo educado, do povo culto. ${ }^{37}$

Em evidente aproximação ao discurso do Estado e da Igreja, a psiquiatria caminhou na mesma direção. Em sua tese de doutoramento em Medicina pela Faculdade de Medicina do Rio de Janeiro, em 1919, Oscar dos Santos Pimentel "lamentava que o progresso das luzes fosse freado no século XIX, ao ressuscitar a superstição". ${ }^{38} \mathrm{Em}$ suas próprias palavras:

Vão longe o tempo dos fantasmas, dos lobisomens, das almas penadas e das almas do outro mundo. E no século passado, quando o homem supunha que essa coorte apavorante se havia embrenhado na treva noite do esquecimento, à sua frente surgia novo flagelo, encasquilhado com o nome de espiritismo ${ }^{39}$.

35 JORNAL SANTUÁRIO DA TRINDADE. Campininha das Flores: Coleção Convento Santo Afonso, 19221925. Ano 4, n. 120.14 ago. 1925.

36 JORNAL SANTUÁRIO DA TRINDADE. Campininha das Flores: Coleção Convento Santo Afonso, 19221925. Ano 4, n. 123.05 set. 1925.

37 Celso Calmon Nogueira da Gama. Chefe de polícia. Processo 651, maço 9. Cartório de Crime de Pirenópolis (GO). 1925. 63f-63v

38 ISAIA, op, cit. p. 68.

39 PIMENTEL, O. dos S. Em torno do espiritismo. Tese (Doutorado em Medicina) - Faculdade de Medicina do Rio de Janeiro, Rio de Janeiro, 1914. p. 23. apud ISAIA, op, cit. p. 68. 
Em todo caso, embora tais argumentos relacionados à superstição tivessem força em face do desejo de inserção do Brasil no caminho do progresso, foi na tentativa de enquadramento do espiritismo como doença mental, passível de contágio epidêmico, que se respaldou de fato tanto a medicina psiquiátrica quanto o próprio catolicismo.

Assim como a sífilis ou a tuberculose, o caráter contagioso do espiritismo representaria um perigo à saúde pública nacional. Conforme analisou Isaia, "como catalisador de energias desconhecidas e primitivas, o espiritismo aparecia como um perigo, capaz de provocar crises de histeria coletiva, transformar homens e mulheres pacatos em feras humanas". ${ }^{40} \mathrm{Uma}$ vez divulgadas tais teses pelas instituições médicas, as mesmas se tornavam um recurso poderoso e de grande credibilidade para uso em argumentos católicos.

Por outro lado, no jornal Santuário da Trindade a expressa maioria das matérias em combate ao avanço do espiritismo se utiliza de supostas notícias, cujo argumento tem sempre em seu bojo o respaldo médico para tratar o espiritismo ora como doença a ser saneada, ora como praga a ser combatida. De início, destacamos quatro notícias divulgadas no periódico em questão:

Anda por ahi um pobre prejudicado que ora está fazendo discursos ora promove subscripções "para salvar o Brazil" ora faz outras maluquices. Dizem-nos que o coitado ficou com o juízo variado porque em uma cidade do sul do Estado frequentava sessões de espiritismo, elle mesmo em momentos lúcidos conta com tristeza que o espiritismo o fez perder o juízo. A quantos o espiritismo tem transtornado a cabeça. o diretor do hospício do Juquery, o grande hospício de São Paulo declarou que grande parte dos doudos que ali estão internados, enlouqueceu por causa do espiritismo. ${ }^{41}$

Em São Paulo suicidou-se no mez passado um jovem estudante. Elle foi levado a este acto de desespero pela leitura de livros espiritistas e pela pratica de espiritismo. Acontece muitas vezes que os que praticam o espiritismo acabam loucos ou suicidam-se. $\mathrm{O}$ espiritismo é por isto um grande inimigo da humanidade, uma praga terrível que, onde entra, causa os maiores estragos. ${ }^{42}$

A senhora Z, moradora em Petropolis, frequentava uma casa espírita e em pouco, começou a fazer sessões em sua casa, sem licença do marido. Passados alguns mezes, dizia Ella ouvir voes e barulhos na casa e que, durante a noite,

40 ISAIA, op, cit. p. 65.

41 JORNAL SANTUÁRIO DA TRINDADE. Campininha das Flores: Coleção Convento Santo Afonso, 19221925. Ano 1, n. 4, 12 ago. 1922.

42 JORNAL SANTUÁRIO DA TRINDADE. Campininha das Flores: Coleção Convento Santo Afonso, 19221925. Ano 1, n. 11, 18 nov. 1922. 
os espíritos cantavam. Quando o marido souve, já era tarde: teve de recolhel-a a uma casa de saúde. Ahi, ultimamente, Ella arrancou um dos olhos e furou o outro, dizendo que não precizava mais dos olhos para se communicar com os espíritos. Acha-se agora internada no Hospicio. ${ }^{43}$

Em Cuba foi condemnada a prisão uma mocinha que propositalmente tinha ateado fogo na casa de seos Paes, queimando-se a casa e toda a mobília. A mocinha declarou que era espírita, e que um espírito lhe tinha dito que o melhor meio de livrar sua casa de espíritos mãos era o fogo. É mais um caso que mostra quantos males causa o espiritismo. Que todos procurem impedir a propagação de uma doutrina tão desastrada. ${ }^{44}$

As quatro supostas notícias em questão revelam características importantes do discurso emitido pelo jornal Santuário da Trindade em combate ao espiritismo goiano. Uma dessas características que nos chama atenção é a diversidade geográfica de atuação do espiritismo que o jornal se preocupava em demonstrar aos leitores. Nas citadas matérias temos notícias de Goiás, São Paulo, Rio de Janeiro e até internacionais (Cuba). ${ }^{45}$ Esta diversidade parece apontar tanto para um caráter de "epidemia espírita", que se alastrava pelo Brasil e pelo mundo, como para a necessidade de Goiás exercer o mesmo combate que outros estados e países já estariam realizando. ${ }^{46} \mathrm{Tal}$ combate, pelo que aponta o jornal, estaria nas mãos dos católicos - convocados a repudiarem a propagação do espiritismo, algo como uma "ação preventiva" -, mas fundamentalmente dos médicos, responsáveis pelo "tratamento" de um mal já instalado. ${ }^{47}$

43 JORNAL SANTUÁRIO DA TRINDADE. Campininha das Flores: Coleção Convento Santo Afonso, 19221925. Ano 1, n. 12, 02 dez. 1922.

44 JORNAL SANTUÁRIO DA TRINDADE. Campininha das Flores: Coleção Convento Santo Afonso, 19221925. Ano 2, n. 28, 12 jul. 1923.

45 Destacamos que em nossa pesquisa encontramos matérias referentes ao espiritismo citando ainda outros países, com destaque para França e Estados Unidos.

$46 \mathrm{Na}$ edição de número 16, por exemplo, os editores afirmam que "o espiritismo em sua forma actual teve sua origem nos Estado Unidos. Actualmente, porem, o povo e as autoridades de lá estão bem convencidos que o espiritismo é um cancro que destroe e mata, que traz innumeros males e desgraças. Por isto uniram-se as autoridades civis e religiosas para combaterem com todos os meios este mal tão grande que é o espiritismo" (JORNAL SANTUÁRIO DA TRINDADE. Ano 1. n. 16. 27 jan. 1923).

47 Um exemplo que corrobora nosso argumento pode ser encontrado em edição de número 23: "No Rio de Janeiro enlouqueceram no anno passado mil e tantas pessoas. Os dous médicos mais celebres no tratamento de loucos, dr. Juliano Moreira e dr. Gustavo Ricdel declararam que o maior numero destes casos de loucura foi causado pelo espiritismo. Este facto e esta declaração devem abrir os olhos de todos a respeito do espiritismo e dos estragos que elle causa. Mesmo se não fosse indigno de um homem sensato e ainda mais de um christão, acreditar nas tolices das evocações espíritas, o facto que o espiritismo tem levado muito á loucura, ao suicídio ou ao crime, é tão grave que ninguém pode approvar ou favorecer o espiritismo" (JORNAL SANTUÁRIO DA TRINDADE. Ano 2, n. 23, 05 maio 1923). 
Outra importante característica das matérias citadas é o caráter noticiário das mesmas. Embora os editores do jornal não tenham o cuidado de citar as fontes de suas notícias, a legitimidade de sua fala - enquanto instituição social e religiosa aceita como detentora da competência da verdade dá autoridade às informações divulgadas. Uma vez legitimados, os "boatos" ganham força de verdade, transformando o que seria apenas um ponto de vista sobre um dado acontecimento em algo indiscutivelmente verdadeiro. Segundo Eleonora Brito:

Os boatos funcionam então como fomentadores de imagens que já circulam no imaginário dessas comunidades. Aquilo que antes era apenas intuição de perigo, ganha corpo nas imagens construídas pelos boatos e informações que não se sabe de onde vem. [...] São os boatos. Estes só fazem sentido quando encontram um clima propício à sua divulgação, e é o que acontece com esse discurso que jamais se propõe a provar nada. Alia-se a isto a questão da autoridade discursiva que, ao apropriar-se de uma "informação" dando-lhe seu respaldo, legitima-a automaticamente. ${ }^{48}$

Parece-nos ter sido esse o caso do combate ao espiritismo. Uma série de boatos, verdadeiros ou não, ganharam através das linhas do Santuário da Trindade uma força de verdade que tornaria o avanço espírita perigoso, seja para a saúde pública, seja para o progresso social da nação. Aproveitando-se da força da notícia, diversos outros casos foram divulgados e associados ao espiritismo. ${ }^{49} \mathrm{Em}$ tais casos, tanto a loucura quanto o charlatanismo eram argumentos que reforçavam o "perigo" da propagação "epidêmica" do espiritismo em Goiás. Vejamos mis algumas matérias que reforçam a presente reflexão:

Em São Paulo foi condemnado a um anno e nove mezes de prisão o medico espirita, Estanislao Jacob Arantes que tirou a quantia de 1:500\$000 a um cliente que o consultava sobre a saúde da esposa. 0 médium fez sessão, apagou as lues e na escuridão limpou os bolsos do consultante. Ainda é muito que não disse ou que outro não acreditou terem sido os espíritos os que filaram os cobres. Mas é isto o que é espiritismo, exploração e roubo. ${ }^{50}$

48 BRITO, E. Z. C. de. A construção de uma marginalidade através do discurso e da imagem: Santa Dica e a corte dos anjos em Goiás - 1923-1925. Dissertação de Mestrado - Universidade de Brasília, Brasília, 1992. p. 96.

49 É interessante lembrarmos que os editores do Santuário da Trindade, além de notícias, utilizavam-se também de histórias de reflexão para o combate ao espiritismo. Tais histórias, notadamente sem qualquer pretensão jornalística, ocuparam em algumas edições uma coluna frequente do jornal, de nome "Leituras Amenas", como é o caso, a título de exemplo, das edições de número 7 e 24 de 1922 e 1923, respectivamente.

50 JORNAL SANTUÁRIO DA TRINDADE. Campininha das Flores: Coleção Convento Santo Afonso, 19221925. Ano 1, n. 8,07 out. 1922. 
Há dous annos um doutor espiritista affirmou que conseguiu tirar photographias de espíritos que appareciam quando chamados por uma mulher que servia de médium. Elle escreveu até um livro sobre os resultados de seos esforços e com as photographias por elle tiradas. Agora foi verificado que elle se enganou redondamente ou deixou-se enganar pela mulher que servia de médium. Por meio de mascaras e outros artifícios ella simulava os vultos nebulosos que appareciam e se deixavam photographar. Assim ficou mais uma vez provado que o espiritismo não passa de uma grande mentira e exploração e o doutor que queria provar a verdade do espiritismo, está miseravelmente desmoralisado. ${ }^{51}$

A policia do Rio averiguou que um casal de espiritistas, encarregandose do tratamento de uma pobre louca, quis cural-a a força de pancadas e maltratou-a barbaramente, tanto que se viram no corpo da infeliz os signaes de espancamento. Não é este o primeiro caso em que ficou provado que os espiritistas maltratam crualmente os loucos que elles recebem em seus hospícios para cural-os. É um systema de tratamento que os médicos e toda gente de bem deve reprovar. ${ }^{52}$

A policia da Bahia fechou os centros espíritas. Convenceu-se de que o espiritismo é um perigo para a ordem publica e causador de muitas desordens e crimes e casos de loucura. Por isto afinal decidiu-se a applicar a Lei que prohibe as práticas de espiritismo. É preciso que em toda parte o povo se convença que o espiritismo é uma praga mais perniciosa que a peste. ${ }^{53}$

Esta referida argumentação voltada para o caráter de charlatanismo das práticas espíritas remete tal prática religiosa à condenação criminosa. Conforme refletimos no início do presente artigo, a ação do Estado contra o espiritismo esteve pautada no Código Penal brasileiro de 1890, no qual o espiritismo fora condenado como crime contra a saúde pública. De encontro à Carta Constitucional, cujo conteúdo favorecia a liberdade de culto religioso no Brasil, a condenação às práticas espíritas se baseava tanto no exercício ilegal da medicina quanto no uso do "espiritismo, a magia e seus sortilegios, [...] talismans ecartomancias [...] para fascinar e subjugar a credulidade publica".$^{54}$ Isto significa que, uma vez que o espiritismo era associado ao charlatanismo, que "subjugava a credulidade pública", seria dever do Estado repreender tais práticas. Desse modo, caberia à Igreja prevenir, ao Estado

51 JORNAL SANTUÁRIO DA TRINDADE. Campininha das Flores: Coleção Convento Santo Afonso, 19221925. Ano 1, n. 16, 27/01/1923.

52 JORNAL SANTUÁRIO DA TRINDADE. Campininha das Flores: Coleção Convento Santo Afonso, 19221925. Ano 1, n. 25, 02/06/1923.

53 JORNAL SANTUÁRIO DA TRINDADE. Campininha das Flores: Coleção Convento Santo Afonso, 19221925. Ano 2, n. 29, 28/07/1923.

54 BRASIL. Subsecretaria de Informações. Artigo 157. Código Penal Brasileiro. Rio de Janeiro: Senado Federal, 1890 . 
repreender, e à Medicina curar. Diante de tais obrigações e em face do avanço constante do espiritismo, restou à imprensa católica cobrar do Estado ações mais enérgicas contra os referidos "criminosos", como se pode notar na seguinte matéria:

Do Jornal do Commercio de S. Paulo, tomamos estas considerações: “Quem ler o jornais destes últimos dias ficará, por certos, impressionado com as noticias a respeito de pessoas que se tornaram vítimas das mystificações e dos "trues" dos pseudos propagandistas da sciencia espírita nesta capital. A demência de um guardalivros, chefes de família, e o suicido de uma jovem, são os factos mais recentes. Não faz dois mezes, talvez, suicidou-se uma senhora, num sanatório espírita, nos subúrbios da Capital. Escabrosa, de facto, e por demais escabrosa é a jornada terrena dos infelizes incautos subjugados à vontade descricionaria deste ou daquelle "medium". E o interesse é que esses truões que se intitulam prophetas, Pae, etc, ainda encontram apoio moral de gente de certa responsabilidade no nosso meios social". Mas, qual o principal culpado de tantas desgraças? o Código Penal Brasileiro não condenna de modo claro a pratica do espiritismo? Como, pois, campeia ele desenfreadamente por toda parte? Que faz a nossa policia? E os nossos governantes que providencias tomam? Não é o caso de perguntarmos: Onde estamos e para onde vamos? ${ }^{55}$

Por fim, o terceiro tipo de argumento evidente nas linhas do Santuário da Trindade contra o espiritismo -uma vez que já apresentamos a loucura e a criminalidade como argumentos -, refere-se, não inesperadamente, à religião.Tratando-se de um jornal eclesiástico, não seria de se estranhar que as alegações contra uma prática sobretudo religiosa se desse igualmente por meio de argumentos religiosos.

Segundo Lewgoy,

Desde Allan Kardec os espíritas combatem uma ideia de "religião" calcada no modelo da Igreja Católica, composta de "liturgia", "ritual", "imagens" e "sacerdotes", afirmando uma doutrina de "tríplice aspecto", “cientifico, religioso e filosófico". Implacáveis no combate aos espíritas, os católicos serão os primeiros a brandir a acusação de ação do demônio nas manifestações espíritas, a que se agregará, no século 20, uma singular retórica parapsicológica, usada como arma no combate a espíritas, afro-brasileiros e esotéricos, onde "fraude" e "loucura" serão as explicações mais comuns do transe e da possessão. ${ }^{56}$

55 JORNAL SANTUÁRIO DA TRINDADE. Campininha das Flores: Coleção Convento Santo Afonso, 19221925. Ano 1, n. 22, 21 abr. 1923. Grifo nosso.

56 LEWGOY, op, cit. p. 159. 
Entretanto, mesmo na utilização visível de argumentos religiosos, na prática o que se percebe é uma recorrência expressamente maior de argumentos médicos e criminais. Em um dos raros exemplos de matérias contra o espiritismo que os editores se utilizaram principalmente de recursos religiosos, vemos as seguintes alegações, cujo conteúdo não deixa de fazer menção tanto ao charlatanismo, condenado criminalmente, como à loucura - um argumento propriamente psiquiátrico.

Uma das grandes pragas que flagellam a humanidade é o espiritismo. Um indivíduo qualquer affirma que elle sabe chamar as almas do outro mundo, reúne algumas pessoas em um quarto escuro e eis formada uma sessão espírita ou antes está armado o laço de pegar os bobos. Com effeito que homem de bom senso poderá acreditar que as almas do outro mundo são escravas que tem de apresentar-se e responder a perguntas quando em qualquer parte um sujeito qualquer as manda comparecer? O que é certo sobre o espiritismo, é o seguinte: Em quase todos os casos não apparece nas sessões nenhum espírito, mas tudo quanto ahi se percebe só manejos do chefe da sessão que se aproveita da escuridão para enganar os outros. Nos poucos casos em que apparece um espírito, nunca é a alma que se chamou, mas sim o demônio que assim quer seduzir e perder os homens. Entretanto, é o espiritismo muito pernicioso, porque ensina cousas contrarias a Religião e assim faz os homens perder a fé e porque faz muitíssimas vezes ficar loucas as pessoas que assistem as reuniões. Por isto a Egreja Catholica condemna o espiritismo e prohibe debaixo de peccado mortal a assistência às sessões espíritas. ${ }^{57}$

Sobre esta estreita relação entre argumentos médicos, criminais e religiosos, algumas reflexões são necessárias. Em primeiro lugar, é de salutar importância perceber que a aliança entre os discursos médico e religioso só foram possíveis graças à construção de uma visão do catolicismo como sendo "racional" e "desmagificado". Em uma aula ministrada em 14 de junho de 1905, o professor catedrático de medicina psiquiátrica, Henrique Roxo, deixou claro que tipo de motivações religiosas causaria a histeria e loucura em seus pacientes:

As superstições que se implantam na mente dos degenerados podem leválos à alienação, pelas emoções que acarretam perturbações vaso-motoras. As religiões, praticadas com excesso por impressionáveis, podem concorrer para a alienação, determinando emoções que acarretam perturbações vaso-motoras ou provocando concentrações psíquicas, estados de abstração que provoquem alterações nas secreções internas, redundando tudo em auto-intoxicação. 0 espiritismo, que figura com coeficiente menor

57 JORNAL SANTUÁRIO DA TRINDADE. Campininha das Flores: Coleção Convento Santo Afonso, 19221925. Ano 1, n. 3, 29 jul. 1922. 
nos tempos atuais em que fiz a estatística, influi pelas perturbações emotivas, cujo efeito já tive o ensejo de consignar. ${ }^{58}$

Portanto, para o professor e pesquisador de medicina psiquiátrica, a forma de religião capaz de causar "alienação" e "perturbações vasomotoras" se refere àquelas que são "supersticiosas" e "praticadas com excesso por impressionáveis", enfim, o "espiritismo" e seus correlatos. Nesse sentido, uma religião de culto racional, cuja mistificação permanecia praticamente ausente, como é o caso do catolicismo das igrejas e breviários, não teria qualquer incidência sobre os problemas psicológicos acusados pela Medicina, tampouco sobre os crimes registrados pelo Estado. Quaisquer formas de misticismo, curas, milagres ou qualquer "excesso impressionável", como o foi o caso de Santa Dica, condenado pelo mesmo periódico, teria como resultado a doença e o crime. ${ }^{59}$

\section{CONSIDERAÇÕES FINAIS}

Ao analisarmos as mais variadas matérias em campanha de combate ao espiritismo publicadas no jornal Santuário da Trindade, nos deparamos com argumentos que variam da condenação religiosa ao crime e à doença. No entanto, tais argumentos só podem ser entendidos de maneira mais substancial se percebermos uma tácita aliança entre três instituições que tomaram o avanço do espiritismo como inimigo comum: a Igreja, o Estado e a Medicina. Das três, ao que nos parece, o Estado acabou por servir às outras duas apenas como aparato legal para uma ação mais afetiva de combate às práticas espíritas, uma vez que, presente a criminalização do espiritismo no Código Penal, a cobrança de ações enérgicas do poder público contra tais práticas seria não apenas possível, mas necessária.

Por outro lado, no que diz respeito à Medicina, parece-nos haver uma relação minimamente estreita entre a ascensão da psiquiatria e a conde-

\footnotetext{
58 ROXO, H. de B. B. Moléstias mentais e nevroses. Rio de Janeiro, 1906. p. 33-34. Aulas ministradas durante o ano letivo de 1905 pelo prof. dr. Henrique de Brito Belford Roxo apud ISAIA, op, cit. p. 65. Grifo nosso.

59 Embora seja uma discussão que exija um espaço adequado, o caso de Santa Dica é de fato emblemático neste debate, uma vez que a líder messiânica condenada em campanha pelo Santuário da Trindade foi acusada pelo mesmo, bem como pelo Estado que a julgou em processo criminal, de praticar o espiritismo, magia e seus sortilégios, inculcando a cura de moléstias curáveis e incuráveis, julgando-se capaz de receitar remédios, casar, batizar e até mesmo crismar seus seguidores. Durante seu processo criminal, houve tentativas constantes de provar que seus seguidores teriam sido privados de seus estados mentais saudáveis, com laudos médicos que provariam inclusive sua própria histeria como sendo a causa de suas visões e estados de transe. Sobre o caso de Santa Dica, tanto sobre seu desfecho criminal como em sua condenação pelo Santuário da Trindade, recomendamos nossa dissertação de mestrado, defendida em 2012 na Universidade Federal de Ouro Preto. Ver: GOMES FILHO, op, cit.
} 
nação do espiritismo, seja em vias do discurso do progresso e higienização social, seja pela possibilidade de ver no espiritismo um razoável candidato a oferecer pacientes suficientes para uma campanha que desse valor e credibilidade à nova classe intelectual, política e social em ascensão.

Por fim, a Igreja Católica - em face do fim do regime de padroado, no qual não somente perdia subsídios financeiros do Estado, mas, fundamentalmente, teria de enfrentar a competição das demais religiões agora legalmente aceitas no país - parece ter tido no espiritismo (mas também no protestantismo) uma vítima expiatória que não somente legava ao catolicismo o caráter de "racional", "culto" e "civilizado", mas especialmente possibilitava uma reaproximação do discurso eclesiástico com as esferas intelectuais (no caso, médicas) que ascendiam no Brasil. Desse modo, parece-nos viável pensarmos o combate ao espiritismo nas linhas do Santuário da Trindade como fruto não somente da competição religiosa pós-padroado, mas fundamentalmente de um contexto nacional que exigia do catolicismo um posicionamento claro perante a "nação", ao "progresso" e à "saúde pública" (leia-se "Medicina").

Artigo recebido para publicação em: 19/07/2013

Artigo aprovado para publicação em: 31/03/2014 